\title{
A Estratégia Saúde da Família: motivação, preparo e trabalho segundo médicos que atuam em três distritos do município de Duque de Caxias, Rio de Janeiro, Brasil The Family Health Program: motivation, training and work according to physicians acting at three districts of the city of Duque de Caxias, Rio de Janeiro, Brazil
}

\author{
Ana Caroline de Medina Alves e Silva \\ Médica de Família da Superintendência de Atenção Básica, Edu- \\ cação em Saúde e Gestão Participativa da Secretaria de Estado de \\ Saúde e Defesa Civil do Rio de Janeiro. \\ Endereço: Rua México, 128 sala 403 G, Castelo, CEP 20031-142, Rio \\ de Janeiro, RJ, Brasil. \\ E-mail: carolinemedinaळig.com.br \\ Maria Auxiliadora Monteiro Villar \\ Doutora em Ciências. Coordenadora Adjunta do Programa de \\ Pós-graduação em Saúde da Criança e da Mulher do Instituto \\ Fernandes Figueira/Fundação Oswaldo Cruz. \\ Endereço: Av. Rui Barbosa, 716, Flamengo, CEP 22250-020, Rio de \\ Janeiro, RJ, Brasil. \\ E-mail: doritamvillarøhotmail.com \\ Maria Helena Cabral de Almeida Cardoso \\ Doutora em Ciências. Médica pediatra do Departamento de \\ Genética Médica do Instituto Fernandes Figueira/ Fundação \\ Oswaldo Cruz. \\ Endereço: Av. Rui Barbosa, 716, Flamengo, CEP 22250-020, Rio de \\ Janeiro, RJ, Brasil. \\ E-mail: cardosomhca®iff.fiocruz.br \\ Susana Maciel Wuillaume \\ Doutora em Ciências. Chefe do Departamento de Ensino do Instituto \\ Fernandes Figueira/Fundação Oswaldo Cruz. \\ Endereço: Av. Rui Barbosa, 716, Flamengo, CEP 22250-020, Rio de \\ Janeiro, RJ, Brasil. \\ E-mail: susanamacielœwuillaume.com
}

\section{Resumo}

Analisou-se como o médico do Programa de Saúde da Família (PSF) de Duque de Caxias percebe sua atuação. Foram feitas entrevistas semiestruturadas com 15 médicos que trabalham no primeiro, terceiro e quarto distritos, sendo o primeiro urbano e os demais rurais. Aplicou-se aos dados a análise de conteúdo, na modalidade temática. Os núcleos de sentidos referiram-se à motivação e ao preparo para ingressar na equipe, e a oportunidade que o PSF oferece para estabelecer vínculos com o paciente, reforçando o acolhimento, a escuta e a responsabilidade. Estabeleceram-se: a) a maioria se ressente da opinião que os colegas fazem dela; b) a preparação ofertada é eminentemente teórica; c) vínculo, escuta e responsabilidade são avanços conquistados na realização profissional, e d) as bases da racionalidade médica formatam a organização das práticas, traduzindo uma concepção de saúde que se define pela ausência das doenças. Consubstancia-se uma lacuna entre a realidade e a proposta do governo de fazer do PSF uma via de reorganização da atenção básica.

Palavras-chave: Programa Saúde da Família; Clínica médica; Vínculo. 


\section{Abstract}

The study analyzed how physicians working in Programa Saúde da Família (PSF - Family Health Program) perceive their professional practice in the municipality of Duque de Caxias, state of Rio de Janeiro, Brazil. Semi-structured interviews were conducted with fifteen physicians working in the first, third and fourth districts. The first district is urban and the others, rural. Data was analyzed by content analysis, and the nuclear senses found were associated with motivation and training to carry out the job, and the opportunity the Program offers to establish close personal bonds between physicians and patients, reinforcing the capacity to listen and accountability. The results showed that: a) the great majority resent what their colleagues think about them; b) the offered training is essentially theoretical; c) bonding, capacity to listen and accountability are advances and professional achievements; $d$ ) the modern occidental medical rationality is the base of the practice, health being the absence of disease. It can be said that there is a gap between reality and the government's intention of making PSF become a path to reorient the Brazilian health system.

Keywords: Family Health Program; Medical Clinic; Bonding.

\section{Introdução}

A Estratégia Saúde da Família (ESF), muito conhecida como Programa Saúde da Família (PSF), vem sendo proposta pelo Ministério da Saúde (MS) como uma forma de reorganização da atenção básica com possibilidade de reorientação do sistema de saúde, incorporando como princípios as diretrizes do Sistema Único de Saúde (SUS) - universalização, descentralização, integralidade e participação da comunidade -, estruturando-se a partir da Unidade Básica de Saúde (UBS).

Nas grandes cidades, as unidades da ESF contemplam prioritariamente áreas de maior carência socioeconômica, onde parte da população vive em condições precárias e exposta a problemas como violência e desemprego.

O município de Duque de Caxias faz parte da Região Metropolitana I do Estado do Rio de Janeiro, juntamente com Belford Roxo, Itaguaí, Japeri, Mesquita, Nilópolis, Nova Iguaçu, Magé, Queimados, Seropédica, São João de Meriti e Rio de Janeiro.

Segundo dados do IBGE, é o município mais populoso da Baixada Fluminense, com 798.102 habitantes, pelo senso de 2002, e ocupa 35\% de sua área. É uma região que apresenta inúmeros problemas relacionados a processo de ocupação desordenada, densidade demográfica e altos índices de violência urbana (Brasil, 2005).

O município é organizado em quatro distritos: $1^{0}$ distrito (Centro), onde a maior parte das habitações e as atividades econômicas se concentram; $2^{\circ}$ distrito (Campos Elíseos), no qual se localizam as indústrias de transformação e distribuição de produtos manufaturados; $3^{\circ}$ distrito (Imbariê), área de grandes reservas florestais e estabelecimentos não ocupados e $4^{\circ}$ distrito (Xerém) considerado rural, com poucos núcleos habitacionais (Duque de Caxias, 2002).

A ESF foi implantada no município em junho de 1998 com sete equipes, permanecendo com este número até o ano 200o, quando passou a contar com 23 equipes (Duque de Caxias, 2002).

No ano de 2002, o município aderiu ao Projeto de Expansão e Consolidação da Saúde da Família (Proesf), realizando um novo projeto em que foram contemplados vários itens que consideravam tanto a situação atual quanto a almejada (Brasil, 2003). 
O município reconhecia a necessidade de melhorar o fluxo de acesso do cidadão aos serviços de saúde e acreditava que a ampliação da cobertura da ESF facilitaria o fluxo de atendimento devido à organização da porta de entrada ao sistema pelas unidades do programa. A Secretaria Municipal de Saúde previa construção, reforma, adequação e aluguel para receber novas equipes e promulgava que, para a escolha das áreas de implantação, seriam considerados os aspectos demográficos, a infraestrutura municipal, a disponibilidade de serviços de saúde da região, a dificuldade de acesso aos serviços, aspectos epidemiológicos, urbanização, entre outros. Em um primeiro momento, seriam escolhidas áreas que contavam com equipes de profissionais voltadas para atenção básica, compostas principalmente de médicos e enfermeiros que já integravam a rede municipal.

O projeto municipal considerava a capacitação de recursos humanos prioridade e tinha como perspectiva a ampliação das equipes para quatro supervisores técnico-administrativos (enfermeiros) e uma equipe multiprofissional de apoio técnico composta de médico, nutricionista, psicólogo e assistente social. Como estratégia para integração com a rede, propunha parcerias para desenvolver e implementar sistemas de referência e contrarreferência mais organizados, construir novas práticas e criar protocolos de atenção, além de estudos avaliativos sobre a satisfação do usuário e a participação comunitária.

Segundo dados do Sistema de Informação da Atenção Básica (SIAB) da Coordenação Estadual do Programa de Agentes Comunitários de Saúde/ Programa Saúde da Família (PACS/PSF), Duque de Caxias apresentava, em junho de 2006, 61 equipes de saúde da família (correspondendo a 17,92\% de cobertura municipal do PSF) e 33 equipes de saúde bucal.

Dentro desse contexto, passados quatro anos de adesão ao Proesf, este trabalho objetivou analisar como o médico percebe sua atuação na ESF de Duque de Caxias, considerando prioritariamente a motivação da escolha, os benefícios profissionais auferidos e as relações estabelecidas com os pacientes.

\section{Metodologia}

Realizou-se um estudo de campo, exploratório, apoiado na abordagem qualitativa, tomando como sujeitos da pesquisa 15 médicos das equipes que integram a ESF do Município de Duque de Caxias.

A amostra foi de conveniência, privilegiando-se os profissionais que atuam no primeiro, no terceiro e no quarto distritos por serem respectivamente o mais urbano e os mais rurais. Foram levados em consideração os seguintes critérios: trabalhar no ESF há mais de três anos e estar cadastrado na listagem do Sistema de Informação da Atenção Básica (SIAB), fornecida pela Secretaria de Estado de Saúde do Rio de Janeiro (SES/RJ), no mês de janeiro de 2006. Para manutenção do sigilo, os depoentes foram nomeados pela letra E seguida de um número correspondente à ordenação das entrevistas.

A técnica utilizada foi a da entrevista semiestruturada, que permite ao pesquisador obter os dados de forma mais flexível, uma vez que utiliza perguntas abertas e fechadas, seguindo um roteiro temático que, no caso em questão, abordou quatro eixos: a escolha de trabalhar na ESF, o tipo de treinamento realizado, a percepção da experiência que está sendo vivida e a relação com os pacientes.

A análise dos dados ocorreu através de análise de conteúdo, na modalidade temática, adaptada do proposto por Bardin (1977).

Optou-se por apresentar os resultados finais e sua discussão de forma conjunta e seguindo a ordem dos núcleos de sentido alcançados, que foram: a motivação e o tipo de treinamento preparatório para trabalhar na ESF e, principalmente, a qualidade da relação com os pacientes. Se o primeiro foi constituído por dois significados - motivação e treinamento -, o segundo o foi por categorias referidas como ensejadas pela própria conformação da ESF, compreendendo quatro unidades de conteúdo - escuta, vínculo, acolhimento e responsabilidade. Os resultados expostos a seguir apresentam primeiramente a capacitação e a motivação, porém, propositadamente, num segundo item, alongam-se sobre as qualidades de atendimento propiciadas pelo trabalhar com a ESF, refletindo a própria inclinação dos entrevistados para uma discussão mais ampla sobre esse aspecto. 
O projeto que embasou o estudo foi aprovado pelo Comitê de Ética do Instituto Fernandes Figueira da Fundação Oswaldo Cruz, sob parecer n ${ }^{\circ}$ 050/05, de 7 de dezembro de 2005 .

\section{Motivação e Preparo para Trabalhar na ESF}

Nenhum dos médicos entrevistados fez residência médica em medicina de família e comunidade (MFC) ou medicina geral e comunitária (MGC). Treze, porém, exerciam alguma especialidade: três eram pediatras, três eram clínicos, três eram médicos do trabalho, um era gastroenterologista, um era homeopata, um era ginecologista e um era cardiologista. Dois não tinham especialidade e três, além da clínica, tinham feito cursos de especialização em Saúde da Família.

A motivação para trabalhar na ESF, de acordo com todos, foi a possibilidade de receber uma remuneração melhor, associada à insatisfação com o exaustivo trabalho anterior, quer em razão do excessivo número de consultas ou do ritmo intenso dos plantões da emergência. "Na época o salário era considerado bom e depois porque estava desestimulado com a emergência e aquele ritmo de plantão" (E3) é uma declaração que reflete o sentimento geral.

A questão salarial também é vista como problema, pois por receberem salários superiores aos pagos na rede SUS, alguns se ressentem que seus colegas ignorem o tipo de trabalho que desenvolvem, a carga horária de quarenta horas e a dedicação exclusiva, apelidando-os de "marajás da saúde" ou brincando com a sigla PSF dizendo que ela, na verdade, designa "Programa do Salário Fácil“. Os registros retratam a indignação dos entrevistados diante dessas colocações: "Porque os colegas dizem que você ganha muito bem e não faz nada. Mas, não é isso não. A gente trabalha muito, a responsabilidade é muito grande" (E14).

Percebe-se um tom difuso de queixa. Todos evitam tocar na problemática especialistas versus generalistas, atribuindo o que qualificam como "menosprezo" por parte dos pares ao desconhecimento da proposta da Estratégia. Outro elemento adicional é a noção equivocada de atenção primária, uma vez que, se a entendem de forma ampla, os colegas a en- xergam como unicamente representando o primeiro nível de atenção do sistema de saúde, com objetivos restritos, previamente determinados.

Os relatos demonstram que o início do trabalho nas unidades foi difícil. Em parte pelo desconhecimento do trabalho a ser realizado, mas também pela necessidade de uma atuação generalista até então não praticada, conforma atesta E13: “Tem que fazer tudo: clínica médica, ginecologia, pré-natal... Eu fiquei muito assustada. Eu sempre fiz pediatria”.

O Guia Prático do PSF (Brasil, 2001) recomenda que os profissionais, antes de iniciarem as atividades na unidade, passem por um processo específico de capacitações exigidas pela nova prática. 0 documento preconiza que o primeiro treinamento seja o "Introdutório" e que anteceda o início do trabalho.

O treinamento introdutório visa capacitar o profissional para analisar a situação da área de abrangência, identificando os problemas e o potencial que a localidade tem para resolvê-los. Para isso, ao final do curso, todos devem estar aptos a detectar e informar as características de integração do município ao SUS, além de cumprir os princípios operacionais da ESF: definição territorial, adstrição de clientela, organização do processo de trabalho para resolução dos problemas reconhecidos no território, noção da família como foco da assistência; trabalho em equipe interdisciplinar, vínculos de corresponsabilidade entre os profissionais e as famílias assistidas; noção de que as ações devem ser caracterizadas pela integralidade, resolutividade e intersetorialidade e a importância do estímulo à participação social (Brasil, 2001).

Segundo os depoimentos, o treinamento introdutório é eminentemente teórico, tendo como proposta específica esclarecer as diretrizes do programa. E14 ilustra a posição dos demais ao dizer: "As ações que fazem parte do programa de saúde é toda a orientação feita pelo Introdutório".

Verificou-se, entretanto, a partir da análise conduzida que, na maior parte das vezes, os médicos iniciavam suas atividades sem ter feito o "Introdutório", conforme as declarações a seguir demonstram: "Comecei sempre consultando, consultando. Foi uma dificuldade muito grande porque não havia a orientação de ninguém" (E6), e "Só fomos aprender [as diretrizes do programa] depois, quando fizemos 
o curso chamado Introdutório, no qual ensinam a parte teórica" (Eg).

A preparação e a capacitação para a assistência são fornecidas por uma série de outros cursos. 0 Ministério da Saúde (Brasil, 1998) já reconhecia a importância do processo de capacitação e educação dos profissionais da ESF, pontuando que ele deveria ser contínuo e atender às necessidades que o dinamismo dos problemas traz às equipes. Considerava que, além do aperfeiçoamento profissional, a educação continuada era um importante mecanismo no desenvolvimento da própria concepção da equipe e da vinculação dos profissionais com a população.

Os entrevistados relataram a oferta de treinamentos para os profissionais de nível superior, porém as opiniões sobre alguns cursos são divergentes. Percebe-se certa insegurança, traduzida em crítica, verbalizada pela maioria dos entrevistados, de que os treinamentos eram eminentemente teóricos. As afirmações de E5 e E1o constituem bons exemplos: "São aulas que a gente faz. Há a aula, a parte prática não tem não” (E5); “Tem uns cursos preparatórios na prefeitura. Fizeram vários cursos: uns muito bons, outros que não acrescentam nada" (E10).

A insegurança justifica-se diante de um trabalho novo, abrangente, e só será resolvida, realmente, através da experiência cotidiana. Nesse sentido, os cursos servem para dar rumo e visão geral. 0 profissional tem que ter consciência de que nenhum treinamento pode esgotar qualquer assunto. Por esse motivo, as ações devem ser periodicamente supervisionadas e discutidas, e os limites de atuação na assistência, claramente definidos.

A análise do material confirmou que os treinamentos foram realizados sem apresentarem uma sequência pré-estabelecida e programada, tampouco ofertaram um aprendizado mais prático indicando a necessidade de uma educação continuada.

As proposições emitidas pelo Ministério da Saúde (MS) revelam que há conhecimento da necessidade de traçar algumas diretrizes técnicas em relação à educação permanente das equipes, uma vez que coloca, na nova Política Nacional de Atenção Básica, que os conteúdos mínimos do Curso Introdutório e da Educação Permanente para as equipes serão objeto de regulamentação específica (Brasil, 2006).

\section{O Tempo de Consulta: escuta, vínculo, acolhimento e responsabilidade}

Um tema recorrente nas entrevistas é a questão do maior tempo de consulta que a ESF pode disponibilizar para as pessoas. Muitos entrevistados se reportam ao trabalho realizado anteriormente para mostrar que o maior tempo de consulta facilita a escuta, o vínculo e o acolhimento. 0 trecho a seguir é bem representativo da opinião geral: "A gente vem com aquele estigma do posto: mais rapidez [...] Você ouve, mas você não ouve tanto quanto deveria [...]. Você para ouvir não pode ficar olhando para o relógio. Você tem que dar chance, mais linha para a pessoa falar" (E7).

A escuta proporcionada pelo maior tempo de consulta, na visão dos entrevistados, permite que se estabeleça uma relação de respeito e confiança, na qual aquilo que os pacientes dizem ou comentam facilita a percepção de suas necessidades para além daquela que, porventura, originou a consulta ou a conversa.

Valla e colaboradores (2004) referem que, no geral, os médicos que atuam nos serviços públicos não se atêm ao discurso de seus pacientes porque, dentre outros motivos, isso leva tempo, mas reconhecem que a lógica econômica imposta aos serviços públicos disponibiliza pouco tempo para a consulta.

O objetivo do médico é formular uma(s) hipótese(s) diagnóstica(s), que permita(m) realizar uma linha de investigação coerente, recorrendo aos exames complementares para definir o diagnóstico da doença e traçar a conduta terapêutica. No entanto, há que se sublinhar que para formular um diagnóstico são necessárias uma escuta atenta e uma anamnese bem-feita. 0 processo de anamnese é cognitivo e dirigido. Durante seu desenrolar surge, pela operacionalização de um olhar atento e técnico, leitor dos sinais captados pelo exame físico e acrescidos dos sintomas narrados, o caminho para o diagnóstico da possível enfermidade que acomete o paciente. Portanto, o exercício da clínica médica requer tempo para a realização da consulta e, indubitavelmente, competência profissional (Montgomery, 2006). 
$\mathrm{Na}$ análise das entrevistas, novamente, fica evidente que um atendimento adequado não está sendo possível em muitos postos de saúde e emergências do SUS, em função, conforme já apontado, da indisponibilidade de tempo para atender o grande número de usuários. A consequência imediata é que se dificulta o diagnóstico precoce e consequentemente a instituição da modalidade de tratamento pertinente. Portanto, rompe-se um imperativo ético indispensável, quando se pretende instituir num programa a integralidade da assistência.

Mattos (2001) cita que a cobrança de produtividade para consultas médicas e visitas domiciliares, por exemplo, pode impedir um atendimento norteado pelos princípios da integralidade, sobretudo os referidos a uma escuta atenta, à formação do vínculo com o paciente, ao acolhimento e à abertura para outras demandas e compromisso. Este fato se revela nas palavras de E12:

Eles estão mudando totalmente o perfil do programa. Você vê isso aqui em Caxias, que tem um PSF mais ou menos organizado. $\varepsilon$ nos outros municípios? Você entra em contato com colegas de trabalho de outros PSF e eles têm que atender vinte de manhã, vinte à tarde [...] Você équem sabe a programação prevista para aquele dia, mas aí vem a Prefeitura e estabelece o número ( $\left.\varepsilon_{12}\right)$.

A ESF possui muitas características facilitadoras da criação de vínculos: a carga horária de trabalho de 40 horas, a adstrição da população, a inserção comunitária, o trabalho junto às famílias e a presença do agente comunitário de saúde. Isso faz com que o usuário e o profissional se transformem, como percebe bem E5: "É uma pessoa que você vai atender hoje e da qual amanhã você vai saber notícias. Então é um dos princípios da integralidade: o vínculo médico-paciente é uma coisa muito forte, como se você fosse da família mesmo".

A escuta dentro da proposta da ESF pressupõe a abertura para outras necessidades, que não a explícita na queixa. A escuta diferenciada e a maior oportunidade de criação de vínculos possibilitam responder a uma grande parte da demanda por atenção médica e por cuidados terapêuticos, por atingir indivíduos cujo sofrimento traduz, em parte, o crescente empobrecimento da população e a desorganização do tecido social, expressando-se como problemas coletivos de saúde. Sob esse ponto de vista, a nova prática seria uma das estratégias políticas possíveis para lidar, ainda que parcialmente, com a crise da saúde. A afirmação de E11 referenda esse argumento: "Muitas vezes o paciente tem um problema e ele quer ir ao médico para conversar. Senta, conversa e consegue resolver o problema. A pressão que estava lá em cima volta ao normal”.

Mattos (2001) pontua que a integralidade já se faz presente quando o profissional se abre para outras necessidades que não aquelas diretamente ligadas à doença. Todavia, um fato que não se pode perder de vista é que muitas vezes o sofrimento e a demanda por assistência médica, de fato, correspondem a uma doença orgânica que requer um diagnóstico preciso e a competência do médico, como demonstra as palavras de E6: "A demanda é grande. As dificuldades das pessoas são muitas e elas realmente já estão doentes. Você tem que tratar a doença” (E6).

Portanto, a competência médica é necessária e fundamental para a atuação do médico inserido na ESF. Ele tem que ter conhecimento e experiência nas áreas básicas da medicina, habilidade para reconhecer no paciente a doença, tratá-la quando for o caso, identificar sinais que prenunciam gravidade e a necessidade de encaminhá-lo para níveis mais complexos de atendimento.

Lieberman e Stuart (1997) colocam que médicos de família, por trabalharem na interface das ciências biomédicas, comportamental e social, precisam ser hábeis na conduta reducionista, para se aprofundar na natureza biomédica dos problemas de um paciente, mas também precisam integrar uma compreensão das múltiplas influências que atuam num paciente para produzir uma disfunção biomédica. Os autores referem que a incapacidade de compreender esse papel duplo tem o potencial de derrotar fatalmente os melhores esforços clínicos de qualquer profissional.

Alguns, contudo, não percebem a dimensão do seu papel e acreditam que tudo pode ser resolvido com uma "ausculta carinhosa". Nesse sentido, desconhecem o limite para a sua atuação e entendem a integralidade como uma espécie de "doutrina religiosa”. O risco para o paciente amplia-se na medida em que a onipotência do profissional o leva a se perceber como capaz de dar conta de tudo, reunindo em si o 
amplo espectro que a dimensão multidisciplinar engloba, posicionando-se quase como um semideus, tal com fica perceptível no depoimento de E2:

Você atinge mentalmente, emocionalmente. Atinge a alma, a parte emocional que foi esquecida lá no centro cirúrgico, no quarto ano de medicina, ou lá no primeiro ano de anatomia. Então você atinge uma parte que os outros programas não atingem e isso é quase perfeição. Você vira serviço social, psicólogo, psiquiatra, conselheiro matrimonial e conselheiro sexual (E2).

Conforme nos adverte Camargo Jr. (2003): "É imperativo reconhecer que indivíduos isolados, ou mesmo categorias profissionais inteiras, são limitados para dar conta de fato do espectro de demandas apresentadas pelos sujeitos que sofrem. Isto afirma o trabalho interdisciplinar e multiprofissional como necessidade fundamental" (p. 39).

Para Xavier e Guimarães (2004), a escuta, característica desejável da relação entre profissional e usuário do sistema de saúde, está associada ao ato de despir-se da armadura do conhecimento técnicocientífico e dispor-se a ouvir o outro como alguém que sabe algo sobre o mundo e sobre si mesmo.

Esses autores complementam que o ato de escuta e a tradução representa a operacionalização do reconhecimento de um saber que não substitui, mas complementa e dialoga com o conhecimento biomédico. É exatamente essa a posição de E1, quando narra: "Então deixo ele falar dos problemas dele, não só a doença, e explico tudo para ele. Então ele sai daqui satisfeito, entendendo sobre a doença e a adesão ao tratamento é melhor".

Vale ressaltar que muitos entrevistados entendem que é possível compatibilizar a especialização médica com uma compreensão ampliada dos determinantes do processo saúde-doença, tal como discorre E15:

Respeito o sistema que levou a isso, de cada um ter uma especialidade, mas acho que o médico tem que ter uma noção geral das coisas. Ele pode até se especializar, mas essa noção ele não pode perder [...] Às vezes o lado emocional e psicológico do indivíduo atrai dores, patologias que ele pensa que é doença orgânica. Mas não! Às vezes é doença da alma, da carência espiritual. Então você conversa, cria um vínculo com o paciente (E15).
Uma pesquisa recente sobre a relação entre médicos e pacientes no PSF do Estado do Ceará (Caprara e Rodrigues, 2004) evidenciou que o maior tempo de consulta está associado a uma melhora no atendimento, implicando numa anamnese mais apurada, numa explicação mais compreensível do problema que acomete os pacientes e dos procedimentos diagnósticos e terapêuticos, assim como numa avaliação mais realista, por parte do médico, sobre a compreensão do paciente acerca de seu adoecimento e de sua participação na consulta.

Para Campos (2003), o vínculo é algo que ata ou liga pessoas, indica interdependência, relações com linhas de duplo sentido, compromisso dos profissionais com os pacientes e vice-versa. Para o autor, o vínculo depende tanto dos usuários quando da equipe, sendo necessário que o paciente acredite que esta, por um lado, pode contribuir de algum modo para a defesa de sua saúde e, de outro, que os profissionais que a compõe têm compromisso e responsabilidade com a saúde dos que o procuram.

Acolhimento, vínculo e responsabilidade como princípios norteadores na organização da assistência são considerados fatores impulsionadores de reflexões capazes de provocar inovações nos cuidados em saúde (Ayres, 2004).

Assim, quando se estabelece um vínculo com alguém ou com alguma instituição (uma equipe, um centro de saúde), costuma-se transferir afeto a essas pessoas ou instituições (Campos, 2003). Vários dos relatos analisados evidenciaram afetos positivos da população, em especial durante as visitas domiciliares, como pode ser detectado no que conta E1o: "De repente, senti um movimento dentro da casa. Me levaram até a cozinha e notei que o pessoal se mobilizou, na hora, para comprar [o lanche]. Isso faz você se sentir bem [...] recompensado pelo valor que as pessoas te dão".

Parece que os profissionais médicos da ESF têm valorizado, pelo menos no nível do discurso, a importância de se dispor de tempo que propicie a construção do vínculo, do acolhimento e da responsabilidade para com sua clientela, mesmo sem a presença de uma doença comprovadamente orgânica. Mesmo considerando a espécie de vínculo estabelecido, a organização das práticas, compreendendo a prevenção, as atividades de grupo e a demanda espontânea 
ganham dimensões tradicionais à cultura médica (Camargo Jr., 2003).

O ESF é a estratégia apontada pelo MS para a reorganização da atenção básica, e daí advém uma série de atribuições para a equipe, tais como identificar grupos de risco, garantir a integralidade da atenção por meio da realização de ações de promoção da saúde, de prevenção de agravos à saúde e de ações curativas, garantir atendimento da demanda espontânea, realizar ações programáticas e de vigilância à saúde, participar das atividades de planejamento e avaliar as ações da equipe (Brasil, 2006).

No que se diz respeito à prevenção de agravos, as entrevistas demonstram que o objeto de atenção está voltado para a doença. Assim, os médicos entrevistados referem-se à ESF como uma proposição do MS que tem por objetivo atuar com a prevenção das doenças. O depoimento é um bom exemplo: "É uma medicina preventiva para evitar que a pessoa fique doente, ou para evitar que complique as doenças préexistentes que são as doenças crônicas" (Eg).

Não é surpresa este resultado, uma vez que os entrevistados são todos médicos e têm na racionalidade da medicina ocidental contemporânea a base de sua formação. A medicina preventiva também está pautada na mesma racionalidade, tendo como meta: evitar a doença - prevenção primária ou controle da incidência; curá-la - prevenção secundária ou controle da duração, logo, da prevalência; e mitigála - prevenção terciária ou controle de complicações adicionais (Ayres, 2004).

A preocupação com a prevenção, nos moldes descritos anteriormente, fica nítida no relato de E1: "Com todas as dificuldades, a gente consegue muita coisa, consegue que essas pessoas tenham uma visão das doenças, que se tratem, dêem valor, façam preventivo uma vez por ano pelo menos".

A própria definição de grupos de risco traz implícito o foco na doença, a exemplo dos grupos que são organizados e nomeados segundo a doença que os identifica: o grupo de hipertensos, de diabéticos, de hanseníase e outros.

Mas essas constatações, que aparentemente são contraditórias ao ideal de integralidade, não devem ser vistas de forma tão literal ou como obstáculo à implantação da ESF, e merecem algumas considerações.
Primeiro a expressão "saúde”, em sentido amplo, e por isso mesmo indefinido, impossibilita a proposição de objetivos claros. Segundo a racionalidade da medicina ocidental contemporânea não contempla uma visão tão abrangente de saúde como a que vem sendo proposta pela Organização Mundial da Saúde (OMS). O raciocínio clínico está direcionado aos aspectos biológicos, mas isso não quer dizer que exclua a compreensão de outros determinantes do processo saúde-doença. Portanto, faz-se necessário que o médico compreenda os limites de sua atuação e perceba a importância da interdisciplinaridade. Uma terceira consideração é que, a partir da demarcação desses limites, e possivelmente de outros, as estratégias de superação poderão emergir. Algumas dessas estratégias dizem respeito à inserção do profissional no seio da família e da comunidade sob seus cuidados, ao tipo de escuta estimulado nessa relação "médicopaciente", ainda que o paciente aqui represente um grupo de indivíduos, e à noção da necessidade de construir vínculo, de acolher e de responsabilizar-se pelo paciente que demandou os cuidados. Como diz um entrevistado: "Eu tenho que olhar o outro. Eles não pensam a longo prazo, como eu; pensam no que vão ter para comer na janta. Comecei a ver que nunca tinha pensado por esse ângulo. Tenho que adequar aquilo que eu penso que é bom, com aquilo que para eles é bom realmente" $\left(\mathrm{E}_{7}\right)$.

Favoreto e Camargo Jr. (2002) já sinalizavam que as ações de educação em saúde, promovidas por médicos e enfermeiros da ESF, valorizavam os mecanismos de transmissão de informação, em especial, o "ensino" de hábitos "saudáveis" de vida e normas higiênicas, considerando que estavam cumprindo seu papel na redução dos agravos à saúde. O que nos remete ao movimento sanitarista do século XIX e ao surgimento da pediatria como especialidade da medicina e, paralelamente, à necessidade de cuidadosa vigilância para que erros outrora cometidos não se repitam.

Os depoimentos sugerem que a participação dos médicos nas atividades de educação em saúde, quando presentes, ocorrem em forma de palestras. Muitos relatos a respeito das palestras sugerem que há uma transmissão de conhecimento daqueles que o detêm (os profissionais) para os receptores (os doentes) desinformados. Por exemplo, conforme, 
reflete E3: "É o tal negócio, quando você começa a passar aqueles conhecimentos para a comunidade, ela própria vai transferindo aquilo para outros".

A saúde da família, como estratégia de organização da atenção primária, deve enfatizar a promoção e a prevenção sem descuidar da parte curativo-reabilitadora. Muitos médicos compreendem que a prevenção deve fazer parte das atividades da ESF, mas a análise das entrevistas sugere que há dificuldades para a realização dessas atividades.

Uma das questões que contribuem para que a parte curativo-reabilitadora venha sendo mais desenvolvida, possivelmente, é o fato de ela ser a mais estimulada durante a formação médica, estando arraigada em médicos e leigos, conforme exemplificado por E3: "Eu acho que a gente ainda está enraizada no tratamento: vê a saúde como tratamento para a doença em si. A gente traz isso na bagagem e é difícil tirar isso".

Percebe-se a preocupação de que a demanda espontânea limite o tempo de consulta destinado ao paciente e, com isso, a abordagem mais integral. Todos os entrevistados referem que essa demanda espontânea já limita o tempo destinado às atividades de promoção da saúde e prevenção de doenças.

Favoreto e Camargo Jr. (2002) alertam que o direcionamento dos serviços e práticas na ESF, para ações coletivas de prevenção e promoção da saúde, pode dar margem a atendimentos abstratos em relação à representação e à demanda da população. Essa população continuaria buscando respostas para necessidades singulares, como as expressas em suas angústias ou em seus sintomas mal definidos.

Mattos (2001) considera que, para que seja alcançada a integralidade, é necessário que a organização das práticas esteja voltada para a articulação entre assistência e práticas de saúde pública, o que necessariamente gera tensão entre a demanda espontânea por consulta e a criação pelos serviços de demanda programada. $\mathrm{O}$ autor ressalta que os serviços de saúde atendem predominantemente demandas individuais e têm na assistência médica o principal recurso tecnológico disponibilizado em escalas de acesso progressivamente mais difíceis.

Campos (2003), por sua vez, propõe quatro alternativas para a definição de prioridades e, consequentemente, para a redução da demanda.
A primeira delas seria destacar, durante o trabalho cotidiano, os casos que merecem atenção especial para que se agende retornos periódicos, visitas e atendimento em grupo. A segunda seria realizar a análise das fichas familiares de cadastramento elaboradas pelos agentes de saúde, identificando os indivíduos que merecem algum tipo de atenção especial, tais como: encaminhamento para especialistas, grupos de apoio e agendamento para consultas periódicas. A terceira seria priorizar os grupos de risco para os quais há programa de saúde estruturado. Dentro desses grupos, seria importante identificar as pessoas com maior vulnerabilidade de ordem orgânica, subjetiva ou social. A última sugestão é que as equipes estejam abertas a prioridades construídas por outros parceiros do sistema, ressaltando-se a importância do trabalho de visita dos agentes de saúde como profissionais que podem indicar prioridades para a equipe.

No entanto, demonstrando outra vez que é no exercício da prática que se vai delineando a extensão do problema e os ajustes necessários para enfrentálo, observa-se em vários depoimentos a queixa de que os agentes comunitários de saúde precisariam ser mais qualificados e mais bem remunerados para exercerem seu trabalho. Os entrevistados relatam, inclusive, que os treinamentos para essa categoria são muito menos frequentes. Assim, por exemplo, E3 declara: "Eu acho fundamental eles terem até mais [treinamentos]. Eles estão adentrando uma residência, conversando, então eles têm que saber o que eles vão garimpar em alguém” (E3).

Não há como discordar de Favoreto e Camargo Jr. (2002), uma vez que se constata que não basta que sejam implantadas ações de promoção, prevenção e/ou cura, pois outros elementos são necessários para a construção de uma integração ética entre a dimensão subjetiva, a social e a tecnobiológica. Questões que, conforme a análise dos depoimentos, demonstraram-se pouco aprofundadas no processo de implantação e desenvolvimento da ESF no município de Duque de Caxias.

\section{Considerações Finais}

Se a inserção na ESF, para os entrevistados, por um lado, favorece uma abordagem paciente/indivíduo 
mais completa, por outro, a visão equivocada dos demais colegas, inseridos na rede SUS, dificulta o diálogo com a rede de referência, o que vem, paulatinamente interferindo na reorganização da atenção básica com possibilidade de reorientação do sistema de saúde, conforme a proposição do MS. Para a equipe médica dos distritos 1, 3 e 4 de Duque de Caxias, seus pares preconceituosamente os percebem como muito bem remunerados, ignorando o trabalho que realizam, inclusive, a concepção ampla e fundamental de prevenção primária com a qual trabalham.

Todos valorizam os laços de união intra e interequipes da ESF, construindo uma espécie de rede de apoio mútuo cuja função é suprir as lacunas deixadas quer pela capacitação insuficiente quer pela fragilidade do funcionamento da proposta da integralidade e de seus princípios.

Os vários treinamentos oferecidos tendem a ser mais teóricos e a focalizar os aspectos biológicos. A possibilidade de adquirir novos conhecimentos, contudo, ainda estimula a permanência desses profissionais nas equipes. Mas, de maneira geral, a nova prática é apreendida em função da abordagem individual nas consultas, no exercício cotidiano de escutar, traduzir sintomas em sinais, checá-los via exames complementares, trabalhar na adesão do tratamento, enfim, agenciar os princípios da semiologia médica, ponto de partida para o soerguimento da(s) hipótese(s) diagnóstica(s), elaborando dia a dia o raciocínio clínico.

Em nenhum momento o trabalho se propôs a avaliar a qualidade do atendimento, porém os relatos foram fortemente sugestivos de que, mesmo que a prática na ESF responda por certo aprimoramento da competência clínica, ela, por si só, não basta.

De certa forma, todavia, a maioria dos entrevistados ruma para uma visão mais global de seu paciente, entrevendo no processo saúde-doença elementos não restritos ao mundo das lesões orgânicas, mas incluindo variáveis psicológicas e socioeconômicas, aquelas que desde sempre integraram a história dos saberes e ações articuladas às estruturas sociais, às instituições culturalmente construídas pelos homens, às representações que eles fazem da realidade e a própria constituição de uma consciência histórica.

\section{Referências}

AYRES, J. R. C. M. Cuidado e reconstrução das práticas de saúde. Interface - Comunicação, Saúde, Educação, Botucatu, v. 8, n. 14, p. 73-92, 2004.

BARDIN, L. Análise de conteúdo. Lisboa: Ed. 7o, 1977.

BRASIL. Ministério da Saúde. Secretaria de Assistência à Saúde. Coordenação de Saúde da Comunidade. Saúde da família: uma estratégia para a reorientação do modelo assistencial. Brasília, DF, 1998.

BRASIL. Ministério da Saúde. Departamento de Atenção Básica. Guia prático do programa saúde da família. Brasília, DF, 2001.

BRASIL. Ministério da Saúde. Projeto de expansão e consolidação da saúde da família. Brasília, DF, 2003.

BRASIL. Ministério da Saúde. Secretaria de Gestão Participativa. $2^{\circ}$ Seminário de Gestão Participativa: fórum de Conselhos Municipais de Saúde da Região Metropolitana I. Brasília, DF, 2005. (Série D - Reuniões e Conferências).

BRASIL. Ministério da Saúde. Portaria n 648/ GM de 28 de março de 2006. Aprova a Política Nacional de Atenção Básica estabelecendo a revisão de diretrizes e normas para a organização da Atenção Básica, para o Programa Saúde da Família e o Programa de Agentes Comunitários de Saúde. Diário Oficial da União, Brasília, DF, 29 mar. 2006. Seção 1, p. 71.

CAMARGO JR, K. R. Um ensaio sobre a (In) Definição de integralidade. In: PINHEIRO, R.; MATTOS, R. A. (Org.). Construção da integralidade: cotidiano, saberes e práticas em saúde. Rio de Janeiro: Fiocruz, 2003. p. 35-44.

CAMPOS, C. E. A. O desafio da integralidade segundo as perspectivas da vigilância da saúde e da saúde da família. Ciência e Saúde Coletiva, Rio de Janeiro, v. 8, n. 2, p. 569-584, 2003.

CAPRARA, A.; RODRIGUES, J. A relação assimétrica médico-paciente: repensando o vínculo terapêutico. Ciência e Saúde Coletiva, Rio de Janeiro, v. 9, n. 1, p. 513-535, 2004. 
DUQUE DE CAXIAS. Secretaria Municipal de Saúde. Coordenadoria de Saúde da Família. Projeto municipal de expansão da saúde da família. Duque de Caxias, 2002.

FAVORETO, C. A. O.; CAMARGO JR, K. R. Alguns desafios conceituais e técnico-operacionais para o desenvolvimento do programa de saúde da família como uma proposta transformadora do modelo assistencial. Physis, Rio de Janeiro, v. 12, n 1, p. 59-75, 2002.

LIEBERMAN, J. A.; STUART, M. R. Praticando medicina biopsicosocial. In: RAEKEL, R. E. (Org.). Tratado de medicina de família. Rio de Janeiro: Guanabara Koogan, 1997. p. 50-55.

MATTOS, R. A. Os sentidos da integralidade: algumas reflexões acerca de valores que merecem ser defendidos. In: MATTOS, R. A.; PINHEIRO, R. (Org.). Os sentidos da integralidade na atenção $e$ no cuidado à saúde. Rio de Janeiro: Abrasco, 2001. p. 39-64.
MONTGOMERY, K. How doctors think: clinical judgment and the practice of medicine. New York: Oxford University, 2006.

VALLA, V. V.; GUIMARÃES, M. B.; LACERDA, A. Religiosidade, apoio social e cuidado integral à saúde: uma proposta de investigação voltada para as classes populares. In: PINHEIRO, R.; MATTOS, R. A. (Org.). Cuidado:as fronteiras da integralidade. São Paulo: Hucitec; Rio de Janeiro: Abrasco, 2004. p. 103-117.

XAVIER, C.; GUIMARÃES, C. Uma semiótica da integralidade: o signo da integralidade e o papel da comunicação. In: PINHEIRO, R.; MATTOS, R. A. (Org.). Cuidado: as fronteiras da integralidade. São Paulo: Hucitec; Rio de Janeiro: Abrasco, 2004. p.133-155. 